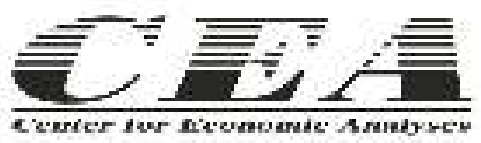

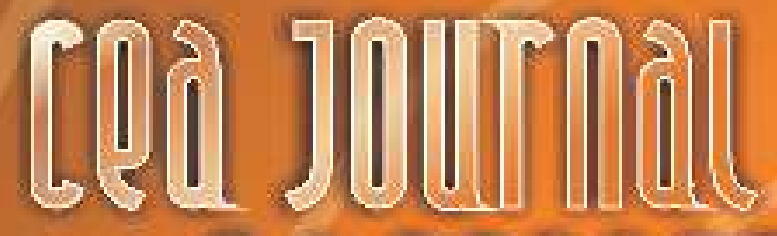
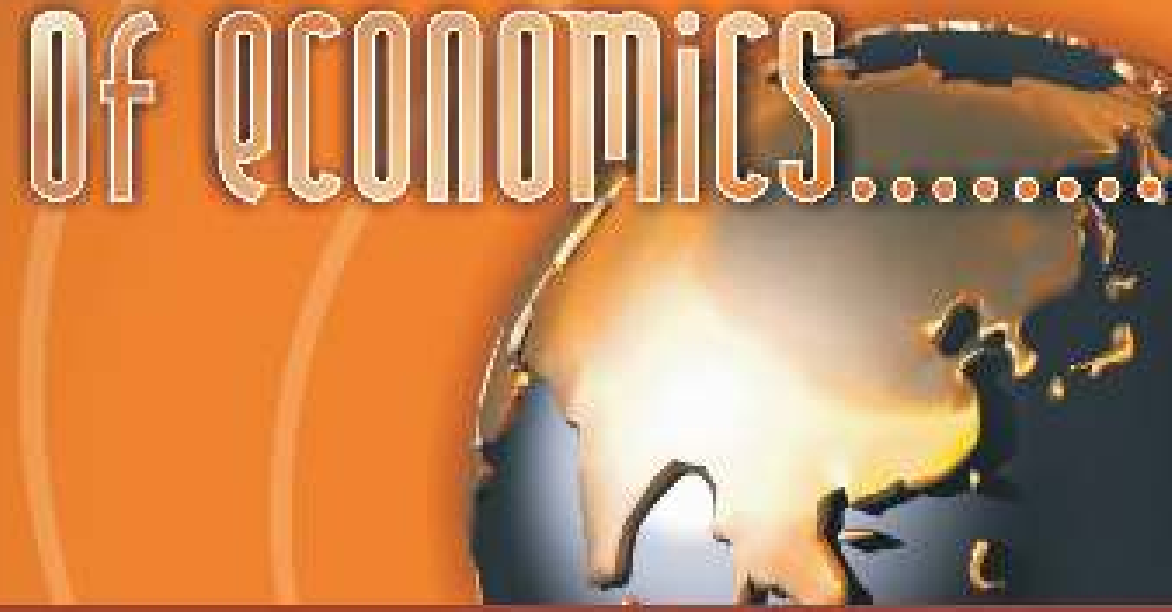

ISSN 1857-5250

UDK 33

Price: 300 MKD (5 EUR)

Volume 12

Issue 2

1-100 pages

Skopje, Macedonia

December 2017 


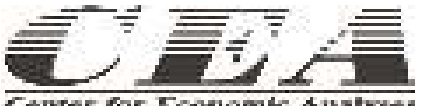 \\ CEA Journal of Economics
}

\author{
ISSN 1857-5269 \\ UDK 33 \\ Volume 12, Issue 2 \\ Skopje, December 2017 \\ International Journal
}

International editorial Board and Reviewers:

Marjan Nikolov, PhD, President of CEA (Editor-in-Chief) Bryan Roberts, Ph.D.

Senior economist at Econometrica Inc USA

King Banaian, Ph.D.

Professor in the Department of Economics at St. Cloud State University USA

Giorgio Brosio, Ph.D.

Professor of Public Economics, University of Turin, Italy. Nevenka Hrovatin Ph.D.

Professor of Public Economics, University of Ljubljana, Slovenia

Dubravka Jurlina Alibegovic, Ph.D.

Director of the Institute of Economics, Zagreb, Croatia William Bartlet, Ph.D.

Visiting Senior Fellow, European Institute, London School of Economics and Political Science

Borko Handziski,

Senior Economist at the World Bank, USA

BorceTrenovski, Ph.D.

Professor at the Faculty of Economics- Skopje, UKIM, Macedonia

Anto Bajo, Ph.D.

Professor at Institute of Public finance and Faculty of Economics and Business Zagreb.

\section{DISCLAMER:}

The opinions put forth in this publication represent the views of their authors. 


\section{Contents}

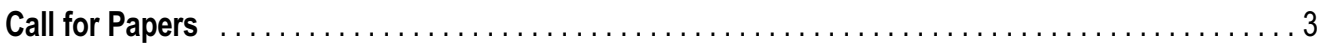

THE POVERTY REDUCING EFFECT OF HEALTH - THE CASE OF REPUBLIC OF MACEDONIA $\ldots \ldots .5$

Shenaj Hadzimustafa - Remzije Rakipi - Marjan Nikolov

EFFICENCY OF THE MACEDONIAN BANKING SECTOR: A NON-PARAMETRIC APPROACH

Katerina Fotova Čiković - Violeta Cvetkoska

EVALUATING ORGANIZATIONAL EFFECTIVENESS

Dragan Gocevski - Marjan Nikolov

THE MACROECONOMIC DETERMINANTS OF HOUSEHOLD

WELFARE IN SADC: A QUANTILE REGRESSION APPROACH

Strike Mbulawa

SYMMETRIC AUCTIONS: FINDING NUMERICAL SOLUTIONS BY USING AUCTION SOLVER

Dushko Josheski

ASPECTS OF THE NAME DISPUTE BETWEEN MACEDONIA AND GREECE:

SYMBOLS, CONFLICT AND ECONOMIC COSTS

Nenad Markovic - Marjan Nikolov

CEA Journal of Economics

Volume 12, Issue 2

1 - 100 pages

Skopje, Macedonia

December, 2017 


\title{
SYMMETRIC AUCTIONS: FINDING NUMERICAL SOLUTIONS BY USING AUCTION SOLVER
}

\author{
Dushko Josheski ${ }^{30}$
}

\begin{abstract}
This essay theoretically investigates symmetric types of auctions and provides simulation for the different types of statistical distributions that bidders follow in order to determine the maximum bid, Expected revenue for the auctioneer, Expected payment by bidders, Expected utility of the bidders, probability that item is unallocated. In addition, the subject of interest of this paper are three types of auctions: FPA (first price auction, Dutch type, SPA (Second price auction, English auction, Vickrey auction), APA (all-pay auctions)
\end{abstract}

\section{Introduction}

Symmetric auctions are widely used in practice. These are types of auctions where bidders submit sealed bids, and the highest bid is winning. ${ }^{31}$ The payments are determined as an anonymous function of bids, (Deb \&Pai 2016).Symmetric auctions are having rules, which are anonymous and non-discriminatory, which is why they are so popular in practice, despite the fact that they do not achieve seller's revenue maximisation when buyers are heterogeneous. For instance, first price auctions(FPA) are more profitable than the second price auctions (SPA) in a case of risk averse buyers and when risk aversion coefficient is higher the difference is larger. So it is plausible that FPA is more profitable than SPA, (Klempeper 1999).Klemperer asserts that in second price or ascending bid auction, winner pays a price set by a runner-up (second best), and by revenue equivalence, must bid the expectation of this price in a first price auction. So the price is fixed in FPA and random but with the same mean in SPA. This means that the price is riskier in SPA. Therefore, risk averse seller prefers first-price auction to a second sealed-bid auction, and prefers the second price sealedbid auction to an ascending open auction.

30) Dushko Josheski, PhD Assistant professor, University Goce Delcev-Shtip, +389(75)954602, dushkojosheski@gmail.com 


\section{Interactions between markets and institutions-The case of auctions}

McAfee and McMillan (1987), define auctions as market institutions with an explicit set of rules that are determining resource allocation and prices on a basis of bids from the market participants.

On the other hand institutions are rules that define conditions by which market messages (offers, demands, and accepts) are being traded, and lead to allocation of resources and process, (Smith2001).If in the economy there exist $n$ agents, i.e. $i=1,2 \ldots . n$ and each of them chooses a message $\mu_{i}$, than the allocation of the resources $x i$ towards agent $i$ is defined as :

\section{Equation 1}

$x_{i}=\eta\left(\mathrm{m}_{1}, \mathrm{~m}_{2}, \ldots . m_{i}, \ldots . . m_{n}\right)$

In the previous expression $\eta$ are the rules of allocation. Rules of allocation are institutionally defined rules. As an example one can take auctions and their rules. Let's suppose that bidder $i$ outs a highest bid. In such case following applies:

\section{Equation 2}

$x_{i}=\eta\left(m_{1}>m_{i}>m_{n}\right)=1, x_{k}=0 ; \forall_{k} \neq 1$

In this case $m_{l}$ is the highest bid, and agent $i=1$ puts a highest bid. Henceforth, agent 1 will win the auction. At first when agent 1 will make the bid, nobody knows who will win the lot (An item or set of items for sale in an auction). But the other on-site bidders know, that none of the other $k$ agents will not like to raise the bid, so that the rules of the institution tell us that $x_{1}=1$ and $x_{k}=0$. Some of the most successful internet auction houses such as eBay and Amazon are using second price auctions, by which bidder with highest bid will win the lot., but pays a price equal to the small increment (growth) on top of a second highest bid. On-site bidder can offer and "reserve price", which is a maximum price and which is used to compete the others with prices. Some auction houses such as eBay have fixed closing time, while on Amazon closing time is continued as long as few minutes pass without bid (ten minutes on Amazon). In the eBay type of auction model there exist $n$ bidders, $i=1,2, \ldots n$. Minimal offer is $m$ (reserve price), and the least increment is $\zeta$, which is assumed to be constant. ${ }^{32}$ Reserve price should be higher than the current price, and the last reserve price ("Hammer price") established by the last bidder, i.e. bidder cannot lower its last reserve price which was set, (Ockenfels\&Roth 2003). Highest reserve price is not revealed. Auction history shows the last price and shows the time when price was put by the bidder. Auctioneer can bid at any time $t \in[0,1] \cup 1$. Reaction time of other bid of second bidder $t^{\prime}<1$. Earliest time of reaction is set with $t_{n}$ and $t_{n}>t^{\prime}$, and is close to one, and so $t^{\prime}<t_{n}>1$. On the eBay auctions there are no dominant strategies. Bid caller (auctioneer), in this auctions can pay some value $v_{j}$, distributed by some known distribution. ${ }^{33}$ Auctioneer who will win the auction with some price $p$, earn the difference between the price he likes to pay, and the price that actually wins the auction $v_{j}$ - $p$, auctioneer who does not won, does not gets zero. In the eBay auctions that are second price of the auctioneer type of auctions not with private value auctions $v_{j}$, there are no dominant strategies $v_{j}>m+\zeta$. The number of auctioneers is $2, i=2$, and by assumption if $i>2$, other auctioneers do not auction. There is no dominant strategy for the player $j$ who has value $v_{j}>m+\zeta$, which is best response for any strategy of the player $j$, which is the best response to any strategy of the player $i$. Let's suppose that the strategy, $i$, is to set minimal bid $m$ when $t=0$, i.e. at the beginning of the auction, and to bid furthermore always when there is highest bid, but if he is not the auctioneer with the highest bid than he will set bid $b>v_{j}+\zeta$. Contrary to this strategy, best response of the player $j$ is not to bid at any time peri-

32) i.e. , $\frac{\partial \zeta}{\partial \rho}=c$, where, $c$ is constant.

33) This strategy for value which the player could bid immediately applies only for the beginning of the auction, or in any time between the beginning and the end of the auction. 
od, $t<1$, and not to bid $v_{j}$ when $t=1$. Result from this strategy for player $j, p\left(v_{j}-m-\zeta\right)>0$, which means that no other strategy when $t=1$ cannot contribute to higher result to $j$. But, if we assume that the strategy of the player $i$ is not to bid in any of the times offered, than the strategy of the player $i$ who answers the bid only when $t=1$, that will provide him the expected result $p\left(v_{j}-m\right)<v_{j}-m$, which is a result that $j$ could achieve from the strategies offered $v_{j}$ when $t=0$, or at any given period of time when $t<1$. Best strategy for the player $i$ is $p\left(v_{j}-m-\zeta\right)>0$, which is a strategy of player $j$, because best strategy of $j$ was not to bid if $t \neq 0$. Consequently, this is a proof that there is no dominant strategy. In a standard auction model of the eBay institution, it has been specified minimal opening bid, but not the price, which is a seller's reserve price. Seller can choose public bid but also additional reserve price below which he cannot sell. In the previous example reserve price is lower so that the post-sale negotiation be avoided. ${ }^{34}$

\section{First price auction (sealed first bid auction strategically equivalent to Dutch auctions)}

In this auction scheme each buyer submits a bid $b \geq 0$ for the object. The bids are sealed, and no bidder has information about the bids of other opponents. The object is allocated to the bidder with the highest bid. Highest bidder pays the bid; other bidders pay nothing. Variance in the Dutch auctions is

For the Dutch type of auctions variance of price is:

\section{Equation 3}

$$
\begin{aligned}
\sigma_{p d}^{2}=\int\left(p_{d}-\bar{p}_{d}\right)^{2} d p(v)=\int_{0}^{1}\left(\frac{n-1}{n} v-\frac{n-1}{n+1}\right)^{2} n v^{n-1} d v \\
=\int_{0}^{1} \frac{n^{2}-1}{n^{2}} v-\frac{(n-1)(n+1)}{(n+1)^{2}} n v^{n-1} d v=\frac{(n-1)(n+1)}{n^{2}} v \\
-\left.\frac{(n-1)(n+1)}{(n+1)^{2}} n v^{n-1}\right|_{0} ^{1}=\frac{\frac{n-1-n^{2}(n-1)}{n^{2}}}{n+1} \\
=\frac{(n-1)(n+1)(1-n)}{n^{2}(n+1)}=\frac{(n-1)(1-n)}{n^{2}}
\end{aligned}
$$

In the Dutch model of auction, buyers gain is $v-p=v-\left[\frac{n-1}{n}\right] v=\frac{v}{n}$; where $v$ is the highest drawn value, range of possible gains is from 0 to $\frac{1}{n}$. While, in the English type of auction gain could vary from 0 to 1 , Vickrey (1961)

\section{Vickrey type of auction (sealed-bid)}

This auction scheme is different in the one presented in (Vickrey1961), which is used by Google and Yahoo in their on-line advertisement programs. Vickrey (1961) auction scheme, is different from the type of scheme of proxy auctions on eBay, by the fact that bids are not closed, i.e. current highest bid ${ }^{35}$ is always public. In Vickrey type of auction, bidders submit their bids sealed, without knowing other members in the auction bids, and in this type of auction highest bid wins, but the price paid is second highest bid. This result is Pareto

34) On this way there is incentive agent not to bid above its own bid if he is the highest bid caller because of the fear reserve price not to exceed his initial bid.

35) Current highest bid is equal to the second best bid plus increment change, i.e. $m+\zeta$ 
optimal. This auction is efficient because the winner is the auctioneer for whom the lot has highest value. Achievement of Pareto optimal result on imperfect markets is difficult. Market imperfection in Vickrey model is in the fact that buyers and sellers are very few in number to ignore consequences of their actions on price but on the other hand there are not enough participants in the market in overt or tacit (collusions) market actions. Vickrey in his model describes one marketing agency, through which all sales of goods and procurements must be done. If we imagine homogenous rectangular distribution of the auction in limits 0 to 1 , and even though number of players is $i>1,2, \ldots n$, from which for all of them there exist corresponding value in the distribution $v_{t}$ and are biding one price, while probability for first $n$ - 1 players to draw corresponding value for them is $[0, v]$ while the n-thplayer would draw corresponding value between $[v, v+d v]=v^{\mathrm{n}-1} d v$, this value is from the value $d p_{1}(v)=n v^{\mathrm{n}-1}$. Price of every bid is given as $p_{d i}=\left(\frac{n-1}{n}\right) v$. Expected price in this case is given with the following expression:

\section{Equation 4}

$\bar{p}_{d}=\int_{0}^{1} p d p_{1}(v) d v=\int_{0}^{1}\left(\frac{n-1}{n}\right) v n v^{n-1} d v=\frac{(n-1)\left(v n v^{n-4}\right)}{n} d v=\frac{n-1}{n+1}$

Previous case is when one has definite integral, i.e. distribution goes from 0 to 1 , and the result applies if $n>-1$, if there is unlimited distribution than the result is:

\section{Equation 5}

$$
\begin{aligned}
& \bar{p}_{d}=\int p d p_{1}(c) d v=\int \frac{(n-1)\left(v n v^{n-1}\right)}{n} d v= \\
& \frac{(n-1) n}{n} \int v v^{n-1} d v=\frac{(n-1) n}{n} \int v^{n} d v=\frac{(n-1) n}{n} \frac{v^{n+1}}{n+1}+C=\frac{(n-1) \cdots v^{n+1}}{n+1}+C
\end{aligned}
$$

Probability that the second best price will be realized is $\frac{n}{n+1}$, and the probability that this price is in the interval between $[v, v+d v] n(n-1) v^{n-2}(1-v) d v$, meaning that the average price is:

\section{Equation 6}

$$
\bar{p}_{c}=\int v d p_{2}(v)=\int_{0}^{1} n(n-1)\left(v^{n-1}-v^{n}\right) d v=(n-1)-\frac{n(n-1)}{n+1}=\frac{n-1}{n+1}
$$

Again expected value of the bidders is the expected value of the excess $\frac{n}{n+1}$, and the value of lot won by the successful bidder $\frac{n}{n+1}$. This applies for progressive type of auctions, , and for Dutch auctions. ${ }^{36}$ But the price variance is different in both types of auctions. ${ }^{37}$ For the SPA (second price auction theory) variance is

\section{Equation 7}

$$
\begin{aligned}
\sigma_{\varepsilon_{d l}^{2}}^{2}=\int_{0}^{1}(v & \left.-\frac{n-1}{n+1}\right)^{2} n(n-1)\left(v^{n-2}-v^{n-1}\right) d v \\
& =\left.\left(v-\frac{n-1}{n+1}\right)^{2} n(n-1)\left(v^{n-2}-v^{n-1}\right)\right|_{0} ^{1}=\left(1-\frac{n-1}{n+1}\right)^{2} n(n-1) \\
& =\left(1-2 \frac{n-1}{n+1}\right)^{2} n(n-1)=\left(1-2 \frac{n-1}{n+1}+\frac{n^{2}-2 n+1}{n^{2}+1}\right) n(n-1) \\
& =\frac{\left[2(n+1)(n+1)^{2}+n^{2} 2(n+1)-4 n(n+1)+2(n+1)\right] n(n-1)}{2(n+1)(n+1)^{2}} \\
& =\frac{n+2\left[(n+1)^{2}+n^{2}-2 n+1\right] n(n-1)}{(n+2)(n+1)^{2}} \\
& =\frac{(n+2) n(n-1)\left[(n+1)^{2}-(n-1)^{2}\right]}{(n+2)(n+1)^{2}}=\frac{2(n-1)}{(n+2)(n+1)^{2}}
\end{aligned}
$$

36) English auctions are such type where it is begun with lowest (reserve prices) and it is going to higher price. English auctions are of open type.

37) Dutch type of auction. is a type of auction, that begins with highest bid that decreases until some auctioneer does accept the price, or accepts proposed reserve price. 
Variance in the gain is even larger from Dutch to English model of auction. Revenue equivalence theorem is a central topic in the auction theory. This theory confirms that if there are $n$ risk neutral agents, that do independent and personal evaluation of some auction good, and valuation follows cumulative distribution $F(v)$, which is ascending probability distribution of a continuous set of choices $(v, v)$. Than every auction mechanism (every institution auction), in which lot will be allocated towards the agent for which it has highest value $v$, and every agent with a valuation of good $v$ has utility 0 , generates exact same revenue, which lead every bidder to make the same payment. Mechanism of lot allocation taken into consideration here is following: expected value of lot for the agent $i$ is $u_{i}(v)$, while the probability that the agent $i$ will win the auction is $P_{i}(v)$, in the equilibrium of the auction (when the lot is saled), and afterwards it follows the agents strategy $v$, this strategy is given by a following expression:

\section{Equation 8}

$$
u_{i}(\bar{v})=\bar{v} P_{i}(\bar{v})-E\left(\text { paynent } \bar{v}_{i}\right)
$$

This means that the utility of agent, is dependent on the average value by which he values lot, which is multiplied with the probability that he will win the auction minus the average value of agents $i$ payment, which he will do for the selected lot. In the equilibrium:

\section{Equation 9}

$$
u_{i}(v) \geq u_{i}(\bar{v})+(v-\bar{v}) P_{i}(\bar{v})
$$

$v$ type agent, values the lot with $v-v$, more than agents $v$ lot valuation. Inequality applies because the deviation must be non-profit, i.e. $v-v \geq 0$, here one it can be written that

\section{Equation 10}

$v=v+d v$

Where $d v$ is some marginal value, and $v$ value is larger than $v$ for some marginal value. If in the previous expression $u_{i}(v) \geq u_{i}(v)+(v-v) P_{i}(v)$ one replaces $v$ with $v=v+d v$, one could get :

\section{Equation 11}

$$
u_{i}(v) \geq u_{i}(v+d v)+(v-v+d v) P_{i}(v+d v)
$$

With the rearrangement one can get:

\section{Equation 12}

$$
u_{i}(v) \geq u_{i}(v)+d v P_{i}(v)
$$

Value of the utility for the agent $i$ for $v$ valuation, one can get as a sum of utility $u_{i}(v)$, plus the sum from probability that lot $x$ will be allocated to him, which is equal to $P_{i}(v)$, ie.:

\section{Equation 13}

$$
u_{i}\left(v_{i}\right)=u_{i}(v)+\int_{v}^{v_{i}} P_{i}(v) d v
$$

Because there are two possible outcomes of the auction, agent wins the lot and agent does not win the lot, $(0,1)$, i.e. as it is said in the theorem at the beginning $(v, v)$, meaning that the agent of type $v$ will never won the game, and his utility will be zero $u_{i}(v)=0$. Furthermore, every player has equal probability that will win the lot in the two type of auctions (English and Dutch) $P_{i}\left(v_{i}\right)$. From the equation, $u_{i}(v)=v P_{i}(v)-E($ payment $v_{i}$ ), for the $i$-th agent we have : 


\section{Equation 14}

$$
u_{i}\left(v_{i}\right)=v_{i} P_{i}\left(v_{i}\right)-E\left(\text { payment } v_{i}\right)
$$

This means that expected payoff in the two mechanisms $(v, v)$, is equal and amounts to E(payment $\left.v_{i}\right)$.

\section{Symmetric model case}

This case applies when coefficient of risk aversion is zero. Whether one chooses Constant relative risk aversion (CRRA), ${ }^{39}$ or Constant absolute risk aversion (CARA), ${ }^{38}$ if the risk aversion coefficients are zero, and reservation price $(r=0)$ revenue equivalence holds. In this case expected revenue $E(R)$, from the auctionto the auctioneer is the same in the First price auction (Dutch auction) and in the Second price auction (English auction, Vickrey type of auction). So in the case where revenue equivalence holds (risk neutral case), utility to the bidders is:

\section{Equation 15}

$$
U(c)=c
$$

In the previous expression $c$ represents consumption, and in the risk neutral case such as this bid functions (symmetric equilibrium bid functions) are:

\section{Equation 16}

$b(v)=\left(\frac{n-1}{n}\right) v$

In the case of a pure strategy equilibrium, where player 1 (bidder) reveals, bidder's valuation is common knowledge, so the rival bidders can anticipate bid of player 1 . This bid will be denoted as $v_{\mathrm{o}}>0$, unless $v_{1}=0$. Best response of the closest rival ( $i$-th bidder) top the bidder 1 rival will be to bid as in an auction with $n$ - 1 bidders, and a common knowledge reserve price $b_{0}$ which will be equal to $v_{0}$. The equilibrium bidding strategy with $n-1$ bidders and a reservation price of $b_{0}$ and reservation value $v>b_{0}$, is given as: ${ }^{40}$

\section{Equation 17}

$b\left(v_{i}\right)=v-\frac{1}{F^{n-1}(v)} \int_{r}^{v} F^{n-1}(s) d s$

$b_{\mathrm{o}}<v<1$ or zero otherwise. In the previous integral $s$ is a signal;

In the previous expression $b\left(v_{i}\right)$ represents buyers $I$ valuation of the object bid that wins the object and in such a case $v_{i}$ represents bidders $i$ reservation value. And the bidding strategy is strictly increasing function of his reservation value, $v$ represents the private values of the bidders, $x$ represents private information that buyer $i$ has obtained about the objective monetary valuation of the object $F^{n-1}(x)$ is buyers probability of winning the lot, while $F^{n-1}(v)$ represents a highest bid. In such a situation winning bid in general is given as: $b(v)=p(v) / F^{n-1}(v)$. In the previous expression $p(v)$ represents expected payment which is equal to: $p(v)=v F^{n-1}(v)-\int_{v_{*}}^{v} F^{n-1}(x) d x$. If $v_{*}=v$ than in FPA and SPA, expected revenue is the same. That is only the case if reservation price is zero. Otherwise the seller will always announce reservation price strictly greater than his personal valuation i.e. $v_{*}>v$, so $: v_{*}=v_{0}+1-\frac{F\left(v_{*}\right)}{F r\left(v_{*}\right)}$. Where $v_{*}$ is a minimum auction reservation value and below this reservation value is not worthwhile bidding, $F\left(v_{*}\right)$ is a probability function

38) This is also known as Arrow-Pratt measure of relative risk aversion. See in (Carl\&Blume1994)

39) This is also known as Arrow-Pratt measure of absolute risk aversion. 
that bidder with valuation $F^{\prime}\left(v_{*}\right)$, will win the lot, and is a first derivative of the probability function. By rewriting and simplifying, we will find bidding function first, we will solve the integral:

\section{Equation 18}

$\int_{r}^{v} F^{n-1}(s) d s=\int_{r}^{v} s^{n-1} d s$

Since signal s=v, Indefinite integral is $\int v^{n-1} d v=\frac{v^{n}}{n}+C$. So to solve definite integral one may apply: Equation 19

$$
\left(\frac{v^{n}}{n}\right) \mid(v=v)=\frac{v^{n}}{n} \text { and }\left(\frac{v^{n}}{n}\right) \mid(v=r)=\frac{r^{n}}{n}
$$

In general solution to the definite integral is :

\section{Equation 20}

$$
\int_{r}^{v} \frac{v^{n}}{n} d v=\frac{v^{n}}{n}-\frac{r^{n}}{n}
$$

Bidding function in the risk averse case where $a=0$, and $r$ is set is given as:

\section{Equation 21}

$$
b\left(v_{i}\right)=v-\frac{1}{v^{n-1}}+\left[\frac{v^{n}}{n}-\frac{r^{n}}{n}\right]
$$

Or in general case for non-uniform distributions bidding function in FPA according to Krishna (2010) is given as:

\section{Equation 22}

$$
\beta(v)=x-\int_{0}^{v} \frac{F(y)}{F(x)} d y
$$

And $F(y)=1-F(x)(\mathrm{F}(\mathrm{x})$ is a CDF of a function $), \mathrm{x}$ signal are drawn from private values distribution $\mathrm{v}$ so $x_{i}=v_{i} e$

Now in the CRRA case, RRA coefficient can take values between zero and 1, utility is given as $(c)=c^{1-a}$, where $a$ is the coefficient of RRA and $a \in(0,1)$. Than the Nash-equilibrium bidding functions will have the following form:

\section{Equation 23}

$$
b\left(v_{i}\right)=v-\frac{1}{F^{\frac{n-1}{1-a}}(v)} \int_{r}^{v} F^{\frac{n-1}{1-\alpha}}(s) d s
$$

And $b_{\mathrm{o}}<v<1$ or zero otherwise.

One general Nash equilibrium biddingstrategy (CRRA case and where $r=0$ ) in FPA is given as:

\section{Equation 24}

$$
b\left(v_{i}\right)=\frac{n-1}{n-1+a}\left(v_{i}\right)
$$

And where $r>0$ i.e. auction is set with the reserve price bidding function is given as: 


\section{Equation 25}

$b\left(v_{i}\right)=v-\frac{1}{F^{\frac{n-1}{1-a}}(v)} \int_{r}^{v v} F^{\frac{n-1}{1-a}}(s) d s$

To solve this we find the indefinite integral solution $(F(v)=v)$ which is :

\section{Equation 26}

$\int v^{\frac{n-1}{1-a}}(x) d x=\frac{v^{\frac{a-n}{-a+1}}}{(a-n)}(a-1)+C$

Namely if $n=\frac{n-1}{1-a}$ than $\int v^{n} d v=\frac{v^{n+1}}{n+1} d v+C ; n \neq-1$

\section{Equation 27}

$\int v^{n} d v=\frac{v^{\frac{n-1}{1-a}+1}}{\frac{n-1}{1-a}+1}+C=\frac{v^{\frac{a-n}{a-1}}}{(a-n)} *(a-1)+C$

Now to evaluate integral at the endpoints

\section{Equation 28}

$$
\begin{aligned}
& \frac{v^{\frac{a-n}{a-1}}}{(a-n)} *(a-1) \|(v=v)=\frac{v^{\frac{a-n}{a-1}}}{(a-n)} *(a-1) \\
& \frac{v^{\frac{a-n}{a-1}}}{(a-n)} *(a-1) \|(v=r)=\frac{r^{\frac{a-n}{a-1}}}{(a-n)} *(a-1)
\end{aligned}
$$

So $\int_{r}^{v} \frac{n-1}{v-\underline{a}} d v=\frac{\frac{a-n}{a-n}}{(a-n)} *(a-1)-\frac{\frac{a-n}{n-n}}{(a-n)} *(a-1)$

So the general bid function in this case when $a>0$ and $r>0$ is given $\mathrm{s}$ :

\section{Equation 29}

$b\left(v_{i}\right)=v-\frac{1}{F^{\frac{n-1}{1-a}}(v)} *\left[\frac{v^{\frac{a-n}{a-1}}}{(a-n)} *(a-1)-\frac{r^{\frac{a-n}{a-1}}}{(a-n)} *(a-1)\right]$

If the coefficient of risk aversion is CARA (Constant absolute risk aversion),ie. $u(c)=1-e^{-a c}$, where $a>0$, than the bidding function is given as:

\section{Equation 30}

$$
b\left(v_{i}\right)=v+\frac{1}{a} \ln \left(1-\frac{e^{-a v}}{F^{n-1}(v)} \int_{e^{a}}^{e^{a v}}\left[F\left(a^{-1} \ln w\right]^{N-1} d w\right.\right.
$$

Or when reserve price and absolute coefficient of risk aversion is set: 


\section{Equation 31}

$$
b\left(v_{i}\right)=v+\frac{1}{a} \ln \left(1-\frac{e^{-a v}}{v^{n-1}} * \frac{1}{2 a} *\left(e^{2 a v}-e^{2 a r}\right) * \log (v)^{n-1}\right)
$$

Where w presents wealth of the bidder. Approximately wealth is approximated by his valuation of the object which is subject to biding at the auction.

\section{All-pay auctions}

In all -pay auctions every bidder pays their bid whether they win or not. In all pay auctions Nash-equilibria (in the case of risk neutrality) mixing strategies of the bidders means that expected sellers revenue is equal to the common value of the prize, ${ }^{41}$ are approximately given by the expression:

\section{Equation 32}

$$
F(b)=\left(\frac{b}{100}\right)^{\frac{1}{n-1}}
$$

Previous expression is valid for all $\mathrm{b}$, if $0 \leq b \leq 100$, in that expression $\mathrm{F}(\mathrm{b})$ also denotes $\mathrm{c}$.d.f of the equilibrium bidding strategy ; see (Gneezy\&Smorodinsky 2006)

In general, in risk neutral case and there is no reserve price set bidding function for All-pay auctions is given as:

\section{Equation 33}

$b_{(a n-p a y)}=v^{n-1}\left[\left(\frac{n-1}{n}\right) * v\right]$

Or $b_{(a n-p a y)}=v^{n-1} * \beta(v)$ where $\beta(v)$ denotes FPA bid-First price auction bid. If the reserve price is set i.e. $r>0$ and bidders are risk neutral $a=0$ than the bidding function in APA auctions is given as:

\section{Equation 34}

$$
b_{(a \|-p a y, r \geqslant 0)}=v^{n-1} * v-\int_{p}^{v} v^{n-1} d v
$$

i.e.

\section{Equation 35}

$b_{(a l l-p a y, r>0)}=v^{n-1} * v-\left[\frac{v^{n}}{n}-\frac{n^{n}}{n}\right]$

in the case where CRRA coefficient is being set bid function in APA auctions takes the following form:

\section{Equation 36}

$$
b_{(a n l-p a y, r \geqslant 0)}=v^{n-1} *\left[\frac{n-1}{n-1+a}\left(v_{i}\right)\right]
$$

If $r>0$ and $a>0$ i.e. there is RRA coefficient set and reserve price at the same 


\section{Equation 37}

$b\left(v_{i}\right)=v^{n-1} *\left[v-\frac{1}{F^{\frac{n-1}{1-a}}(v)} *\left[\frac{v^{\frac{a-n}{a-1}}}{(a-n)} *(a-1)-\frac{r^{\frac{a-n}{a-1}}}{(a-n)} *(a-1)\right]\right]$

In CARA case

\section{Equation 38}

$b\left(v_{i}\right)=v^{n-1} *\left[v+\frac{1}{a} \ln \left(1-\frac{e^{-a v}}{v^{n-1}} * \frac{1}{2 a} *\left(e^{2 a v}-e^{2 a r}\right) * \log (v)^{n-1}\right)\right]$

In general in the previous case with risk averse bidders, bidding functions are approximations the problem of optimization is as follows (according to the software creator Richard M.Katzwer), consider an all pay auction where $\mathrm{n}$ bidders draw IPV from some distribution with cdf on $\left[v_{v}, v_{h}\right]$. And let $\beta:\left[v_{\eta}, v_{h}\right] \rightarrow \mathbb{R}$ denote the symmetric Nash bid function. Bidders are risk averse with utility index $u$ : and initial wealth $W$. A bidder tries to maximize:

\section{Equation 39}

$$
\max _{b} u(W+v-b)\left[F\left(\beta^{-1}(b)\right]^{n-1}+u(W-b)\left(1-\left[F\left(\beta^{-1}(b)\right]^{n-1}\right)\right.\right.
$$

The First order necessary condition (FONC)here is given as:

\section{Equation 40}

$$
\begin{aligned}
0=u^{n}(W+v & -b)\left[F\left(\beta^{-1}(b)\right]^{n-1}\right. \\
& +u(W+v-b)(n-1)\left[F\left(\beta^{-1}(b)\right]^{n-2} F^{\prime}\left(\beta^{-1}(b)\right) \frac{1}{\beta^{\prime}\left(\beta^{-1}(b)\right)}\right. \\
& -u^{\prime}(W-b)\left(1-\left[F\left(\beta^{-1}(b)\right]^{n-1}\right)-u(W\right. \\
& -b)\left(1-\left[F\left(\beta^{-1}(b)\right]^{n-2}\right) F^{\prime}\left(\beta^{-1}(b)\right) \frac{1}{\beta^{\prime}\left(\beta^{-1}(b)\right)}\right.
\end{aligned}
$$

Or since $\beta^{-1}(b)=v$

$$
\begin{aligned}
0=u^{\prime}(W+v & -b)[F(v)]^{n-1}+u(W+v-b)(n-1)[F(v)]^{n-2} F^{\prime}(v) \frac{1}{\beta^{\prime}(v)} \\
& -u^{\prime}(W-b)\left(1-[F(v)]^{n-1}\right)-u(W-b)\left(1-[F(v)]^{n-2}\right) F^{\prime}(v) \frac{1}{\beta^{\prime}(v)}
\end{aligned}
$$

This is a complicated ODE to solve.

\section{Expected revenue (expected payoffs in auctions)}

In the first price auctions expected revenue for the auctioneer for every bid is given as expected payment multiplied by the number of bidders $n$, i.e.:

\section{Equation 41}

$$
\mathrm{E}\left(p_{i} b_{i}, v_{i}\right)=\left(v_{i}-b_{i}\right) \frac{\left(b_{i}\right)^{n-1}}{\left(\frac{n}{n-1}\right)^{n-1}}
$$

$E\left(p_{1}, b_{i}, v_{i}\right)$ is the expected payoff, where $v_{i}$ are independent private values, and revenue is given as: 


\section{Equation 42}

$\mathrm{E}\left(R, b_{i}, v_{i}\right)=\mathrm{E}\left(p, b_{i}, v_{i}\right) * N$

When CRRA coefficient is being set i.e. when bidders are not risk neutral the corresponding expected payoffs (and corresponding revenue) of the bidders are given as:

\section{Equation 43}

$$
\mathrm{E}\left(R, b_{i}, v_{i}\right)=v_{i} * \frac{\left(b_{i}\right)^{n-1}}{\left(\frac{n-1}{n-1+a}\right)^{n-1}}
$$

Where is CRRA coefficient in general when bids for the corresponding probabilities are known (calculated) the expected payoffs (expected revenues for every bidder) are given as:

\section{Equation 44}

$\mathrm{E}\left(R, b_{i}, v_{i}\right)=v_{i} * \frac{\left(b_{i}\right)^{n-1}}{\alpha^{n-1}}$

In the previous expression $\alpha=\left(\frac{n-1}{n-1+a}\right)=\frac{b_{i}}{v_{i}}$ this is because $b_{i}=\alpha+v_{i}$. This is true also when reserve prices is set and coefficient of risk aversion. In the Second price auctions (SPA) the CDF of the revenue functions is calculated as ${ }^{42}$ :

\section{Equation 45}

Revenue $_{\left(S P A, F=0, a \in \mathbb{R}^{+}\right)}=F(y)^{n}+n F(y)^{n-1}(1-F(y))$

$=n F(y)^{n-1}-(n-1) F(y)^{n}$

When reserve price is set in SPA auction, revenue function below reserve price looks like this:

\section{Equation 46}

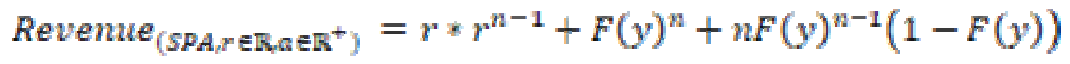

$=r * r^{n-1}+n F(y)^{n-1}-(n-1) F(y)^{n}$

While when independent private values exceed reserve price the functional form of revenue CDF looks same as in the case with no reserve price.

In all pay auctions in general case expected payoffs of the bidders are given as

\section{Equation 47}

$E\left(\right.$ payment $\left._{A P A}\right)=\int \beta(v) d F$

Expected revenue in APA is given as:

\section{Equation 48}

$$
E\left(\text { revenue }_{A P A}\right)=n * \int \beta(v) d F
$$


From the revenue one need to find the private values function first and that is :

\section{Equation 49}

$v=\left(\frac{\beta(v)}{\left(\frac{2}{3}\right)}\right)^{\left(\frac{1}{3}\right)}$

\section{Results from auction solver}

Next, here are presented the results obtained by use of auction solver. Richard M.Katzwer wrote this software. In the First table, we present the results obtained for the risk neutral case and in the second Table, we provide results for the case of risk neutral bidders. ${ }^{43}$

Table 1 Risk neutral bidders, with reservation price zero, number of biiders=3

\begin{tabular}{|c|c|c|c|c|c|c|}
\hline \multicolumn{7}{|c|}{ Risk averse case $\mathrm{CRRA}=0.4 ; \mathrm{CARA}=4.0$ and reservation price $=0.4$; number of bidders $\mathrm{n}=3$} \\
\hline $\begin{array}{c}\text { Type of private } \\
\text { values distribution }\end{array}$ & Auction type & $\begin{array}{c}\text { maximum } \\
\text { bid (right } \\
\text { endpoint of } \\
\text { bid } \\
\text { distribution } \\
\text { b_bar }\end{array}$ & $\begin{array}{c}\text { Expected } \\
\text { revenue for } \\
\text { the } \\
\text { auctioneer } \\
(\mathrm{E}[\mathrm{R}]= \\
\left.\mathrm{E}[\mathrm{m}]^{*} \mathrm{~N}\right)\end{array}$ & $\begin{array}{l}\text { Expected } \\
\text { payment by } \\
\text { bidders } \\
\mathrm{E}[\mathrm{m}]\end{array}$ & $\begin{array}{l}\text { Expected } \\
\text { utility to } \\
\text { bidders } \\
\text { E[u }\end{array}$ & $\begin{array}{l}\text { probability } \\
\text { item is } \\
\text { unallocated } \\
\text { (all bids below } \\
\text { reserve) } \mathrm{P}_{0}\end{array}$ \\
\hline \multirow{3}{*}{$\begin{array}{c}\text { Standard normal } \\
(\mathrm{CRRA}=0.4, \mathrm{r}=0.4)\end{array}$} & $\begin{array}{l}\text { FPA(first price auction, } \\
\text { Dutch type }\end{array}$ & 0.7346317 & 0.5233480 & 0.1744493 & 0.1028037 & 0.0943964 \\
\hline & $\begin{array}{l}\text { SPA(Second price auction, } \\
\text { English auction, Vickrey } \\
\text { auction) }\end{array}$ & 1.0000000 & 0.4798612 & 0.1599537 & 0.1131171 & 0.0943964 \\
\hline & APA(all-pay auctions) & 0.7346317 & 0.0819876 & 0.0273292 & & \\
\hline \multirow{3}{*}{$\begin{array}{c}\text { Standard normal } \\
(\text { CARA }=4.0, \mathrm{r}=0.4)\end{array}$} & $\begin{array}{l}\text { FPA(first price auction, } \\
\text { Dutch type }\end{array}$ & 0.7263772 & 0.5102678 & 0.1700893 & 0.1534737 & 0.0943964 \\
\hline & $\begin{array}{l}\text { SPA(Second price auction, } \\
\text { English auction, Vickrey } \\
\text { auction) }\end{array}$ & 1.0000000 & 0.4798612 & 0.1599537 & 0.1534737 & 0.0943964 \\
\hline & APA(all-pay auctions) & 0.7263772 & 0.0756754 & 0.0252251 & & \\
\hline \multirow{3}{*}{$\begin{array}{c}\text { Log normal } \\
\text { (CRRA }=0.4, \mathrm{r}=0.4)\end{array}$} & $\begin{array}{l}\text { FPA(first price auction, } \\
\text { Dutch type }\end{array}$ & 0.8649665 & 0.7540914 & 0.2513638 & 0.0828988 & 0.0002989 \\
\hline & $\begin{array}{l}\text { SPA(Second price auction, } \\
\text { English auction, Vickrey } \\
\text { auction) }\end{array}$ & 1.0000000 & 0.7077322 & 0.2359107 & 0.0966421 & 0.0002989 \\
\hline & APA(all-pay auctions) & 0.8649665 & 0.1718317 & 0.0572772 & & \\
\hline \multirow{3}{*}{$\begin{array}{c}\text { Log normal } \\
(\mathrm{CARA}=4.0, \mathrm{r}=0.4)\end{array}$} & $\begin{array}{l}\text { FPA(first price auction, } \\
\text { Dutch type }\end{array}$ & 0.8384763 & 0.7290578 & 0.2430193 & 0.1297647 & 0.0002989 \\
\hline & $\begin{array}{l}\text { SPA(Second price auction, } \\
\text { English auction, Vickrey } \\
\text { auction) }\end{array}$ & 1.0000000 & 0.7077322 & 0.2359107 & 0.1297647 & 0.0002989 \\
\hline & APA(all-pay auctions) & 0.8384763 & 0.1559933 & 0.0519978 & & \\
\hline \multirow{3}{*}{$\begin{array}{c}\text { Beta } \\
\text { (CRRA }=0.4, \mathrm{r}=0.4)\end{array}$} & $\begin{array}{l}\text { FPA(first price auction, } \\
\text { Dutch type }\end{array}$ & 0.7735836 & 0.5761506 & 0.1920502 & 0.1036646 & 0.0640000 \\
\hline & $\begin{array}{l}\text { SPA(Second price auction, } \\
\text { English auction, Vickrey } \\
\text { auction) }\end{array}$ & 1.0000000 & 0.5256000 & 0.1752000 & 0.1156296 & 0.0640000 \\
\hline & APA(all-pay auctions) & 0.7735836 & 0.1036405 & 0.0345468 & & \\
\hline
\end{tabular}

43) CRRA and CARA are being used as measures of neutrality or aversity of bidders. 
CEA Journal of Economics :

\begin{tabular}{|c|c|c|c|c|c|c|}
\hline \multirow{3}{*}{$\begin{array}{c}\text { Beta } \\
(\mathrm{CARA}=4.0, \mathrm{r}=0.4)\end{array}$} & $\begin{array}{l}\text { FPA(first price auction, } \\
\text { Dutch type }\end{array}$ & 0.7598812 & 0.5603228 & 0.1867743 & 0.1567281 & 0.0640000 \\
\hline & $\begin{array}{l}\text { SPA(Second price auction, } \\
\text { English auction, Vickrey } \\
\text { auction) }\end{array}$ & 1.0000000 & 0.5256000 & 0.1752000 & 0.1567281 & 0.0640000 \\
\hline & APA(all-pay auctions) & 0.7598812 & 0.0952758 & 0.0317586 & & \\
\hline \multirow{3}{*}{$\begin{array}{l}\text { Uniform } \\
(\text { CRRA }=0.4, \mathrm{r}=0.4)\end{array}$} & $\begin{array}{l}\text { FPA(first price auction, } \\
\text { Dutch type }\end{array}$ & 0.7735836 & 0.5761506 & 0.1920502 & 0.1042956 & 0.0640000 \\
\hline & $\begin{array}{l}\text { SPA(Second price auction, } \\
\text { English auction, Vickrey } \\
\text { auction) }\end{array}$ & 1.0000000 & 0.5256000 & 0.1752000 & 0.1163464 & 0.0640000 \\
\hline & APA(all-pay auctions) & 0.7735836 & 0.1036405 & 0.0345468 & & \\
\hline \multirow{2}{*}{$\begin{array}{l}\text { Uniform } \\
(\mathrm{CARA}=4.0, \mathrm{r}=0.4)\end{array}$} & $\begin{array}{l}\text { FPA(first price auction, } \\
\text { Dutch type }\end{array}$ & 0.7598812 & 0.5603228 & 0.1867743 & 0.1576778 & 0.0640000 \\
\hline & $\begin{array}{l}\text { SPA(Second price auction, } \\
\text { English auction, Vickrey } \\
\text { auction) }\end{array}$ & 1.0000000 & 0.5256000 & 0.1752000 & 0.1576778 & 0.0640000 \\
\hline
\end{tabular}

Next, in Table 2 are presented the results in the risk averse bidders case.

Table 2 Risk averse bidders (CRRA=4.0,CARA $=4.0$ ), with reservation price 0.4 ,number of bidders=3

\begin{tabular}{|c|c|c|c|c|c|c|}
\hline & APA(all-pay auctions) & 0.7598812 & 0.0952758 & 0.0317586 & & \\
\hline \multirow{3}{*}{$\begin{array}{l}\text { Triangular } \\
(\mathrm{CRRA}=0.4, \mathrm{r}=0.4)\end{array}$} & $\begin{array}{l}\text { FPA(first price auction, } \\
\text { Dutch type }\end{array}$ & 0.6901554 & 0.5442205 & 0.1814068 & 0.0892794 & 0.0327680 \\
\hline & $\begin{array}{l}\text { SPA(Second price auction, } \\
\text { English auction, Vickrey } \\
\text { auction) }\end{array}$ & 1.0000000 & 0.5077239 & 0.1692413 & 0.0997395 & 0.0327680 \\
\hline & APA(all-pay auctions) & 0.6901554 & 0.0679635 & 0.0226545 & & \\
\hline \multirow{3}{*}{$\begin{array}{l}\text { Triangular } \\
(\mathrm{CARA}=4.0, \mathrm{r}=0.4)\end{array}$} & $\begin{array}{l}\text { FPA(first price auction, } \\
\text { Dutch type }\end{array}$ & 0.6722348 & 0.5252554 & 0.1750851 & 0.1349865 & 0.0327680 \\
\hline & $\begin{array}{l}\text { SPA(Second price auction, } \\
\text { English auction, Vickrey } \\
\text { auction) }\end{array}$ & 1.0000000 & 0.5077239 & 0.1692413 & 0.1349865 & 0.0327680 \\
\hline & APA(all-pay auctions) & 0.6722348 & 0.0584859 & 0.0194953 & & \\
\hline \multirow{3}{*}{$\begin{array}{l}\text { Kumaraswamy } \\
(\mathrm{CRRA}=0.4, \mathrm{r}=0.4)\end{array}$} & $\begin{array}{l}\text { FPA(first price auction, } \\
\text { Dutch type }\end{array}$ & 0.7372686 & 0.5892777 & 0.1964259 & 0.0925610 & 0.0255160 \\
\hline & $\begin{array}{l}\text { SPA(Second price auction, } \\
\text { English auction, Vickrey } \\
\text { auction) }\end{array}$ & 1.0000000 & 0.5456206 & 0.1818735 & 0.1046092 & 0.0255160 \\
\hline & APA(all-pay auctions) & 0.7372686 & 0.0912166 & 0.0304055 & & \\
\hline \multirow{3}{*}{$\begin{array}{l}\text { Kumaraswamy } \\
\text { (CARA }=4.0, r=0.4)\end{array}$} & $\begin{array}{l}\text { FPA(first price auction, } \\
\text { Dutch type }\end{array}$ & 0.7165197 & 0.5682720 & 0.1894240 & 0.1420239 & 0.0255160 \\
\hline & $\begin{array}{l}\text { SPA(Second price auction, } \\
\text { English auction, Vickrey } \\
\text { auction) }\end{array}$ & 1.0000000 & 0.5456206 & 0.1818735 & 0.1420239 & 0.0255160 \\
\hline & APA(all-pay auctions) & 0.7165197 & 0.0799332 & 0.0266444 & & \\
\hline \multirow{3}{*}{$\begin{array}{l}\text { Gamma } \\
(\mathrm{CRRA}=0.4, \mathrm{r}=0.4)\end{array}$} & $\begin{array}{l}\text { FPA(first price auction, } \\
\text { Dutch type }\end{array}$ & 0.5756602 & 0.2727609 & 0.0909203 & 0.0719515 & 0.4180305 \\
\hline & $\begin{array}{l}\text { SPA(Second price auction, } \\
\text { English auction, Vickrey } \\
\text { auction) }\end{array}$ & 1.0000000 & 0.2592612 & 0.0864204 & 0.0748882 & 0.4180305 \\
\hline & APA(all-pay auctions) & 0.5756602 & 0.0203123 & 0.0067708 & & \\
\hline \multirow{3}{*}{$\begin{array}{l}\text { Gamma } \\
(\mathrm{CARA}=4.0, \mathrm{r}=0.4)\end{array}$} & $\begin{array}{l}\text { FPA(first price auction, } \\
\text { Dutch type }\end{array}$ & 0.5922903 & 0.2713597 & 0.0904532 & 0.1018825 & 0.4156601 \\
\hline & $\begin{array}{l}\text { SPA(Second price auction, } \\
\text { English auction, Vickrey } \\
\text { auction) }\end{array}$ & 1.0000000 & 0.2593647 & 0.0864549 & 0.1018825 & 0.4156601 \\
\hline & APA(all-pay auctions) & 0.5922903 & 0.0208872 & 0.0069624 & & \\
\hline \multirow[b]{2}{*}{$\begin{array}{l}\text { Weibull } \\
\text { (CRRA }=0.4, r=0.4)\end{array}$} & $\begin{array}{l}\text { FPA(first price auction, } \\
\text { Dutch type }\end{array}$ & 0.7011976 & 0.4704638 & 0.1568213 & 0.1001409 & 0.1418659 \\
\hline & $\begin{array}{l}\text { SPA(Second price auction, } \\
\text { English auction, Vickrey } \\
\text { auction) }\end{array}$ & 1.0000000 & 0.4335800 & 0.1445267 & 0.1086913 & 0.1418659 \\
\hline
\end{tabular}


SYMMETRIC AUCTIONS: FINDING NUMERICAL SOLUTIONS BY USING AUCTION SOLVER

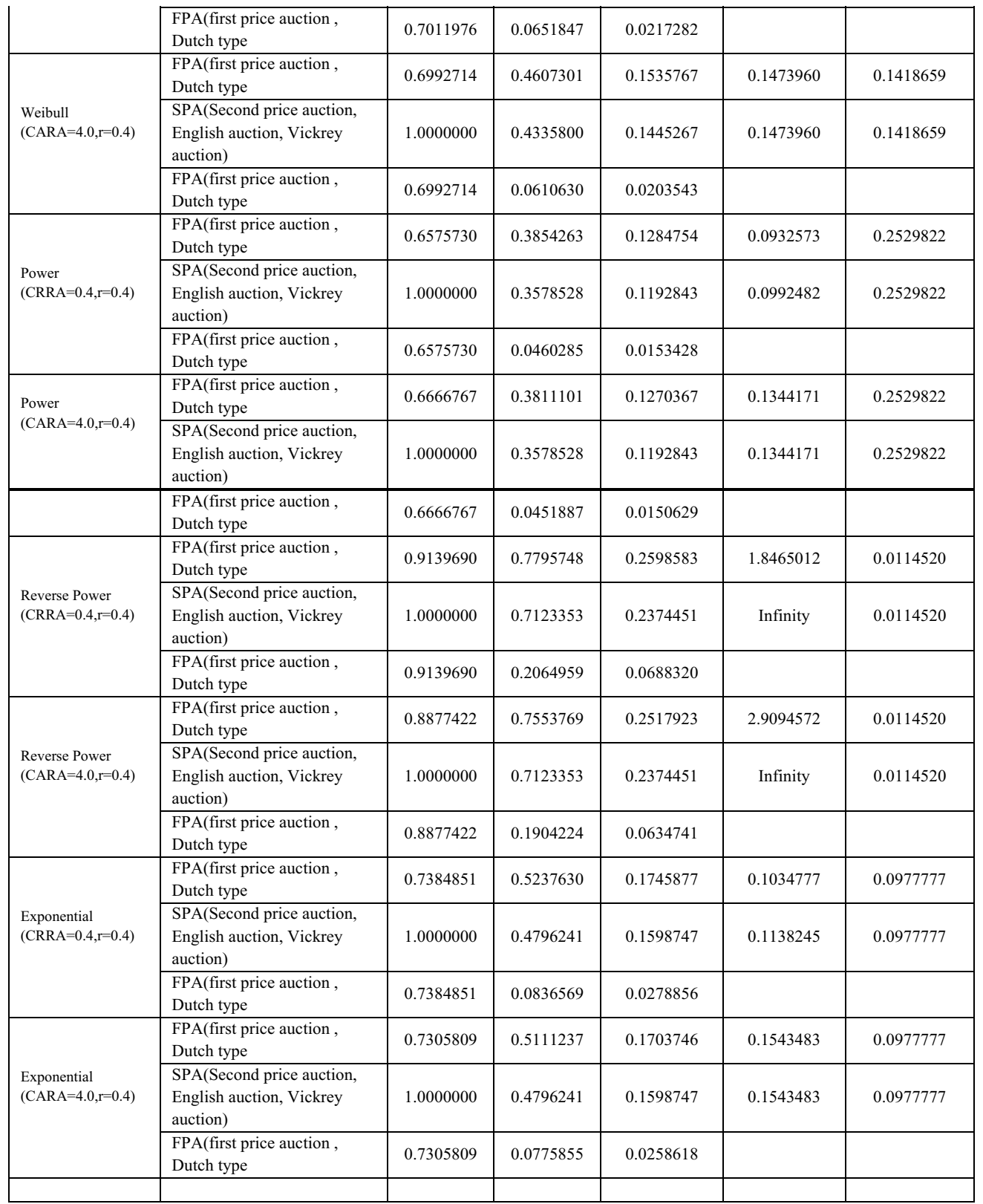




\section{Conclusion}

Hugo Sonnenschein, in his 1983 inaugural Nancy Schwartz Memorial Lecture, argued that is very important to understand how incentives work, i.e. how to create institutional arrangements that induce individuals to behave in certain way so that certain outcome prevails. In 1990s and later, economists have been recognized to the design of several auction like mechanisms such as: US FCC spectrum auctions, 3G auctions in Europe, the allocation of property rights on land at the airports, etc. So, the market design, or market architecture depends on a game theory, in particular games of incomplete information, but most important insights come from auction theory, Menezes, Flavio, M. , Monteiro ,Paulo K.,(2008). Auction mechanism is also very important since it is market clearing mechanism that equates supply and demand. In auctions price formation is explicit, i.e. the rules that determine price formation are well known to all parties involved. This paper provided a theoretical insight how bids are formed in symmetric auctions case, in the three types of auctions FPA, SPA, APA. 


\section{Appendix 1. Distributions in Auction solver software}

\section{Standard Normal distribution function}

In this case $\Phi$ is cumulative distribution, than standard normal function with CDF $\left(\Phi(x)=\frac{1}{\sqrt{2 \pi}} \int_{-\infty}^{x} e^{-(z)^{2} / 2} d z\right.$ and $z=\frac{x-\mu}{\sigma} \mathrm{z}$ is standardized normal value ;in this case of standard normal distribution $\mathrm{z}=\mathrm{x}$ ) given as :

$\mathrm{F}(\mathrm{x})=\frac{\Phi\left(\frac{\mathrm{x}-\mu}{\sigma}\right)-\Phi\left(\frac{\mathrm{a}-\mu}{\sigma}\right)}{\Phi\left(\frac{\mathrm{b}-\mu}{\sigma}\right)-\Phi\left(\frac{\mathrm{a}-\mu}{\sigma}\right)}$

In our case we used standard normal distribution function where $\omega_{L}=0$ and $\omega_{H}=1$ and $\mu=0$ and $\sigma=1$. So this gives :

$\mathrm{F}(\mathrm{x})=\frac{\Phi\left(\frac{\mathrm{x}-0}{1}\right)-\Phi\left(\frac{\mathrm{a}-0}{1}\right)}{\Phi\left(\frac{\mathrm{b}-0}{1}\right)-\Phi\left(\frac{\mathrm{a}-0}{1}\right)}=\frac{\Phi(x)-\Phi(a)}{\Phi(b)-\Phi(a)}$

Also $\omega_{L}$ is the lowest boundary of support where $\mathrm{F}=0$, and $\omega_{H}$ is the highest boundary of support where $\mathrm{F}=1$. Also, $\mathrm{F}(\mathrm{x})$ this is a cumulative function of a distribution. This CDF should be differentiable and strictly increasing function on some interval $\left(\omega_{L}, \omega_{H}\right)$ is a subset form points in the interval $[0, \infty]$.And, $f(x)$ is the probability density function of a distribution, that is derivative of cumulative distribution function $f=F^{\prime}$.

$f(x)=\frac{\frac{1}{\sigma} \phi\left(\frac{x-\mu}{\sigma}\right)}{\Phi\left(\frac{\omega-\mu}{\sigma}\right)-\Phi\left(\frac{-\mu}{\sigma}\right)}$

since in our case $\mu=0$ and $\sigma=1$ we can simplify the previous expression as:

$f(x)=\frac{\phi(\mathrm{x})}{\Phi(\omega)}$

Inverse function of the $\mathrm{CDF}$ is given as:

$F^{-1}(x)=\mu+\sigma \Phi^{-1}\left(x\left[\left(\frac{\mathrm{b}-\mu}{\sigma}\right)-\Phi\left(\frac{\mathrm{a}-\mu}{\sigma}\right)\right]+\Phi\left(\frac{\mathrm{a}-\mu}{\sigma}\right)\right)$ or in our case:

$F^{-1}(x)=\Phi^{-1}(x[(\mathrm{~b})-\Phi(\mathrm{a})]+\Phi(\mathrm{a}))$

\section{Log normal distribution}

In this distribution $\mu$ is a location parameter and it should be $>0$, and $\sigma \geqslant 0$ this is a scale parameter, and $a$ and $b$ parameters should be points drawn as subset for the set of real numbers

$[a, b] \subseteq R$, than CDF of the function would be:

$$
F(x)=\frac{\int_{a}^{x} \frac{1}{z \sigma \sqrt{2 \pi}} \exp \left[-\frac{1}{2}\left(\frac{\ln z-\mu}{\sigma}\right)^{2}\right] d z}{\int_{a}^{b} \frac{1}{z \sigma \sqrt{2 \pi}} \exp \left[-\frac{1}{2}\left(\frac{\ln z-\mu}{\sigma}\right)^{2}\right] d z}
$$


in our case $\mu=0$ but $\sigma=0.5$ so the last expression can be simplified as:

$F(x)=\frac{\int_{a}^{x} \frac{1}{z * 0.5 \sqrt{2 \pi}} \exp \left[-\frac{1}{2}\left(\frac{\ln z}{0.5}\right)^{2}\right] d z}{\int_{a}^{b} \frac{1}{z * 0.5 \sqrt{2 \pi}} \exp \left[-\frac{1}{2}\left(\frac{\ln z}{0.5}\right)^{2}\right] d z}$

And the probability density function given as:

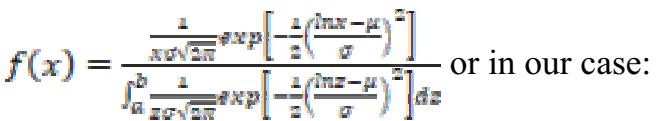

$f(x)=\frac{\frac{1}{s \sigma \sqrt{a \pi}} \exp \left[-\frac{1}{z}\left(\frac{h x}{0.5}\right)^{2}\right]}{\int_{a}^{b} \frac{1}{z^{* a s} \sqrt{2 \pi}} \exp \left[-\frac{1}{2}\left(\frac{h x}{0.5}\right)^{2}\right] d z}$ and $\mathrm{z}=\mathrm{X}$ also could be simplified in the last

expression.

\section{Beta distribution}

In the Beta distribution it should be $\alpha_{n} \beta>0$ so in our case $\alpha=\beta=1$ (uniform distribution) our distribution support values between 0 and 1 , support $=[0.000,1.000]$. The Beta function is a power function on $x$ and its reflection 1$x$, and it is defined as:

$B(a, b)=\int_{0}^{1} x^{a=1}(1-x)^{b=1} d x ; a>0, b>0,0 \leq x \leq 1$

And CDF of this function can be written as:

$F(x)=\frac{1}{\dot{E}(a \cdot b)} \int_{\omega_{L}}^{v(x)} x^{a-1} *(1-x)^{b-1} d x ; \quad$ where $v(x)=\frac{x-\omega_{L}}{\omega_{H}-\omega_{L}}$

PDF of the function is given as:

$f(x)=\frac{1}{\omega_{H}-\omega_{L}} \frac{v(x)^{a-1}(1-v(x))^{b-1}}{B(a, b)}$

With $\alpha=\beta=1$ our Beta distribution turns into standard uniform distribution

$\frac{1}{B(a, b)} x^{a-1}(1-x)^{b-1}$

\section{Uniform distribution}

In the uniform distribution $\omega_{H}>\omega_{L} \geq 0$ and in our case this distributions is supported in the range [0,1].Cumulative distribution function for uniform distribution is given as:

$F(x)=\frac{x-\omega_{L}}{\omega_{H}-\omega_{L}}$

Probability distribution function is given as:

$f(x)=\frac{1}{\omega_{\mu}-\omega_{h}}$

Inverse function is given as:

$F^{-1}(x)=\omega_{L}+x\left[\omega_{H}-\omega_{L}\right]$ 


\section{Triangular distribution}

In our case in the triangular distribution parameters were set as follows: $a=0, b=1$, and $c=0.5$.Requirement here is that $a \leq c \leq b$. Also $\psi \in[0,1]$ this is parameter of uniformity (vertex-common endpoint of two or more rays of line segments). In our case $\psi=0$.

Cumulative distribution function here is:

$$
\begin{aligned}
& F(X)=\psi x+(1-\psi) \frac{(x-a)^{2}}{(b-a)(c-a)} \quad \text { for } x \in[a, c) \text { or } \\
& F(X)=\psi x+(1-\psi)\left[1-\frac{(b-x)^{2}}{(b-a)(b-c)}\right] \text { for } x \in[c b)
\end{aligned}
$$

In our case since $a=0, b=1$, and $c=0.5$ this distribution is a distribution of $x=\frac{\left(x_{2}+x_{2}\right)}{2}, x_{1}$ and $x_{2}$ are two independent random variables. So previous expression in our case would become:

$F_{(0, \ldots, 0.5)}(X)=\frac{(x)^{2}}{(0.5)}=2 x^{2} \quad$ if $0 \leq x \leq 1 / 2 \quad$ or

$F_{(0.5,1-0,0.5)}(X)=1-\frac{(1-x)^{2}}{0.5}=(2 x-1)^{2}$ and for the part $1 / 2 \leq x \leq 1$ it becomes

$F_{(0.5,1,1)}(X)=1-\frac{(1-x)^{2}}{0.5}=2 x^{2}-(2 x-1)^{2}$

$F(x)=\left\{\begin{array}{c}\frac{(x)^{2}}{(0.5)}=2 x^{2} \text { if } x \in(0, \ldots, 0,5) \\ 2 x^{2}-(2 x-1)^{2} \text { if } x \in(0.5, \ldots, 1)\end{array}\right.$

$4 x-(4 x$

Probability distribution function or PDF is a first derivative of the CDF so

$f(x)=F^{\prime}(x)=\left\{\begin{array}{c}4 x \text { if } x \in(0, \ldots, 0,5) \\ 4-4 x \text { if } x \in(0.5, \ldots, 1)\end{array}\right.$

\section{Kumaraswamy or double bounded distribution}

In our case for Kumaraswamy distribution lower and upper bound are $\omega_{L}=0$ and $\omega_{H}=1$ and

$\alpha=\beta=2$. Requirement fulfilled here is that $\alpha_{n} \beta>0$, and $\omega_{k}, \omega_{H} \subseteq \mathbb{R}_{+}$. The CDF of the Kumaraswamy distribution is defined as:

$F(x ; a ; b)=1-\left(1-x^{a}\right)^{b}$

And the probability density function is a first derivative of the previous expression: $f\left(x_{i} a_{i} b\right)=F^{g}\left(x_{i} a_{i} b\right)=a b x^{a-1}\left(1-x^{a}\right)^{b-1}$, for $x \in[0,1]$ and $\alpha_{i} \beta>0$

\section{Gamma distribution}

In our case shape parameter in this distribution $k=0.5$ and scale parameter $\theta=1$ and $a=0, b=1$ so distribution support is support $=[0.000,1.000]$. The Gamma function is defined as: 
$\Gamma(x)=\int_{0}^{\infty} x^{k-1} e^{-x} d x ; k \in(0, \infty)$ (this is also called lower incomplete Gamma function)

CDF of Gamma distribution is given as:

$F(X)=\frac{T\left(k \cdot \frac{x}{b}\right)}{T(k)} x \in(0, \infty)$ or CDF is given as

$F(x)=\frac{\int_{0}^{\infty} x^{k-1} e^{-x} d x}{\Gamma(k)}$

While the probability density function is given as :

$f(x)=\frac{1}{\theta^{k} \Gamma(k)} x^{k-1} e^{-\frac{x}{\theta}}$

Or in terms of shape parameter $k$ and scale parameter $b$, PDF of Gamma distribution can be written as:

$f(x)=\frac{1}{b^{k} \mathrm{r}(k)} \exp \left[(k-1) \ln (x)-\frac{1}{b} x\right] x \in(0, \infty)$ or if we simplify:

$f(x)=\frac{1}{b^{k} \mathbb{R}(k)} * x^{k-1} * e^{-\frac{x}{z}}$ in our case where $\mathrm{k}=0.5, \mathrm{~b}=1$ the last expression would become:

First $\Gamma\left(\frac{1}{2}\right)=\sqrt{\pi}=\sqrt{3.1416}=1.7725 \approx 1.8$

$f(x)=1.8 * \frac{1}{\sqrt{x}} * e^{-x}=1.8 * \frac{1}{\sqrt{x}} * \frac{1}{e^{x}}=\frac{1.8}{e^{x} * \sqrt{x}}$

\section{Weibull distribution}

This is continuous probability distribution. In our case $\omega_{L}=0$ and $\omega_{H}=1$ and $k=1$ which means that the failure rate is constant over time, and $\lambda=1$ this is the scale parameter .And after the Rayleigh distribution $\lambda=\sqrt{2 \sigma}$ since in our case $\lambda=1 \sqrt{2 \sigma}=1$ and $=1 / 2$. Cumulative distribution function of Weibull distribution is given as:

$$
\begin{aligned}
& F\left(x, k_{z} \lambda\right)=1-e^{-\left(\frac{y}{2}\right)^{k}} \text { or alternatively } \\
& F(x)=\frac{1-\exp \left[-\left(\frac{x-\omega_{L}}{\lambda}\right)^{k}\right]}{1-\exp \left[-\left(\frac{\omega_{H}-\omega_{L}}{\lambda}\right)^{k}\right]}
\end{aligned}
$$

Probability density function is given as:

$$
f(x)=\frac{\frac{k}{\lambda^{k}}\left(x-\omega_{L}\right)^{k-1}+\exp \left[-\left(\frac{x-\omega_{L}}{\lambda}\right)^{k}\right]}{1-\exp \left[-\left(\frac{\omega_{\mu}-\omega_{L}}{\lambda}\right)^{k}\right]}
$$

\section{Uniform distribution}

This distribution is $U(a, b)$ in our case $a=0, b=1$, this are minimal and maximal value.

This distribution supports $b \geq a \geq 0$. 
So CDF of a uniform distribution is:

$F(x)=\frac{x-a}{b-a} a \leq x \leq b$

PDF of uniform distribution is given as:

$f(x)=\frac{1}{b-a}$

\section{Power distribution}

This is distribution that is frequently used to model income, financial variables and others. In our case $a=0, b=1, a=0.5$.CDF of this distribution ${ }^{1}$ is given as:

$F(x)=\frac{\eta}{a+1}\left[(x+a+c)^{a+1}-c^{a+1}\right]$

PDF of this distribution is given as:

$f(x)=\eta(x+a+c)^{a}$

In the previous expressions $\eta=(\alpha+1)\left[(x-a+c)^{a+1}-c^{a+1}\right]^{-1}$

\section{Reverse power distribution}

Parameters are the same as in power distribution namely $=0, b=1_{k} a=0.5$. And also $\left[a_{k} b\right] \subseteq \mathbb{R}_{+}$, and $\alpha, 0$ this is a shape parameter.

CDF of this probability distribution is given as:

$F(x)=1-\left(\frac{b-x}{b-a}\right)^{a}$

PDF of this distribution is given as:

$f(x)=\frac{\alpha(b-x)^{\pi-1}}{b-a}$

\section{Exponential distribution}

In our case parameters are set as $\omega_{L}=0$ and $\omega_{H}=1$ and $\lambda=0.5$.CDF of this probability distribution is given as:

$F(x)=\frac{1-\exp \left(-\lambda\left(x-\omega_{L}\right)\right.}{1-\exp \left(-\lambda\left(\omega_{H}-\omega_{L}\right)\right.}$

PDF of this distribution is given as:

$f(x)=\frac{\lambda \exp \left(-\lambda\left(x-\omega_{\varepsilon}\right)\right.}{1-\exp \left(-\lambda\left(\omega_{H}-\omega_{L}\right)\right.}$

Appendix Parametrized distributions in auction solver

${ }^{1}$ See, Katzwer (2011) 
CEA Journal of Economics

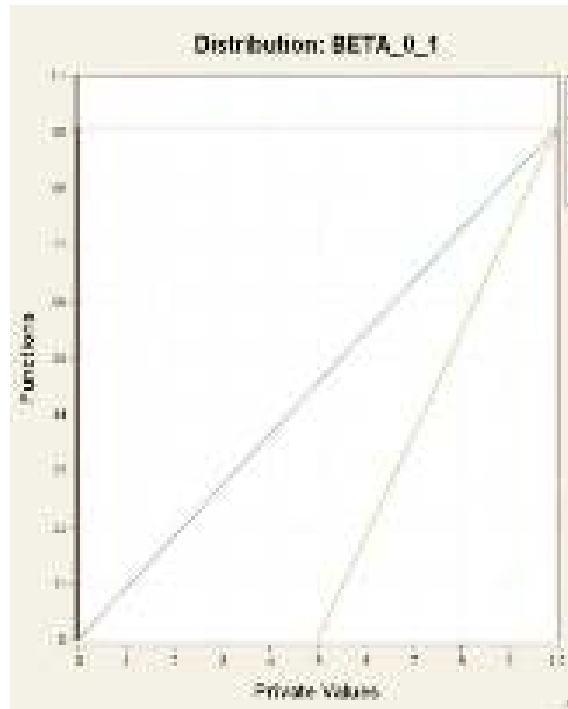

Disdritedian: GaBMA_b_1

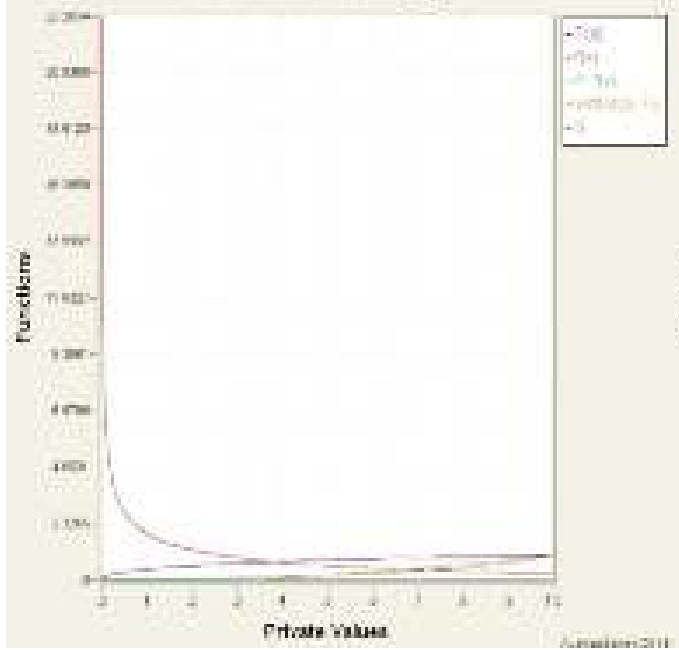

Distribution: EXPORENTHAL_0_t

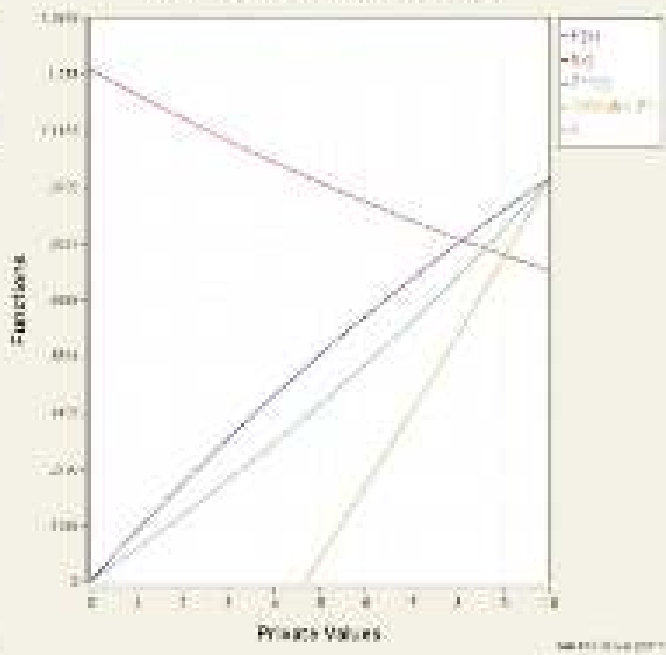

Distrihcian: KUMLRASWRYY_. 1

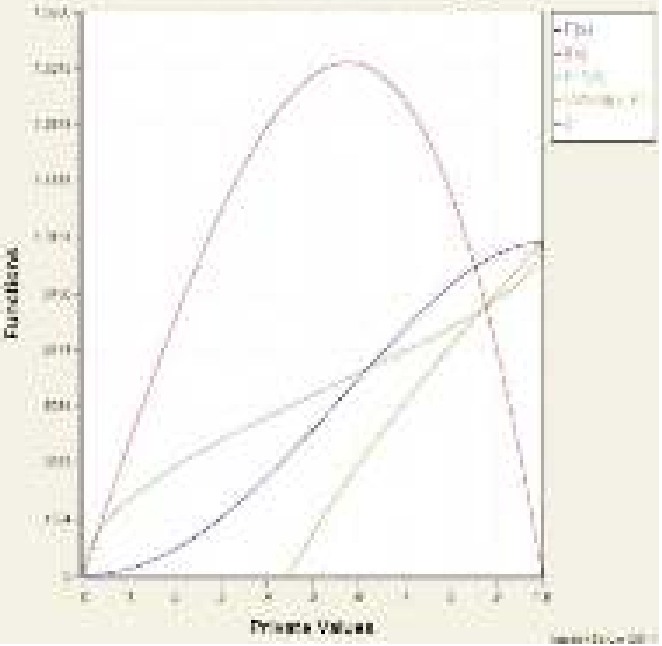




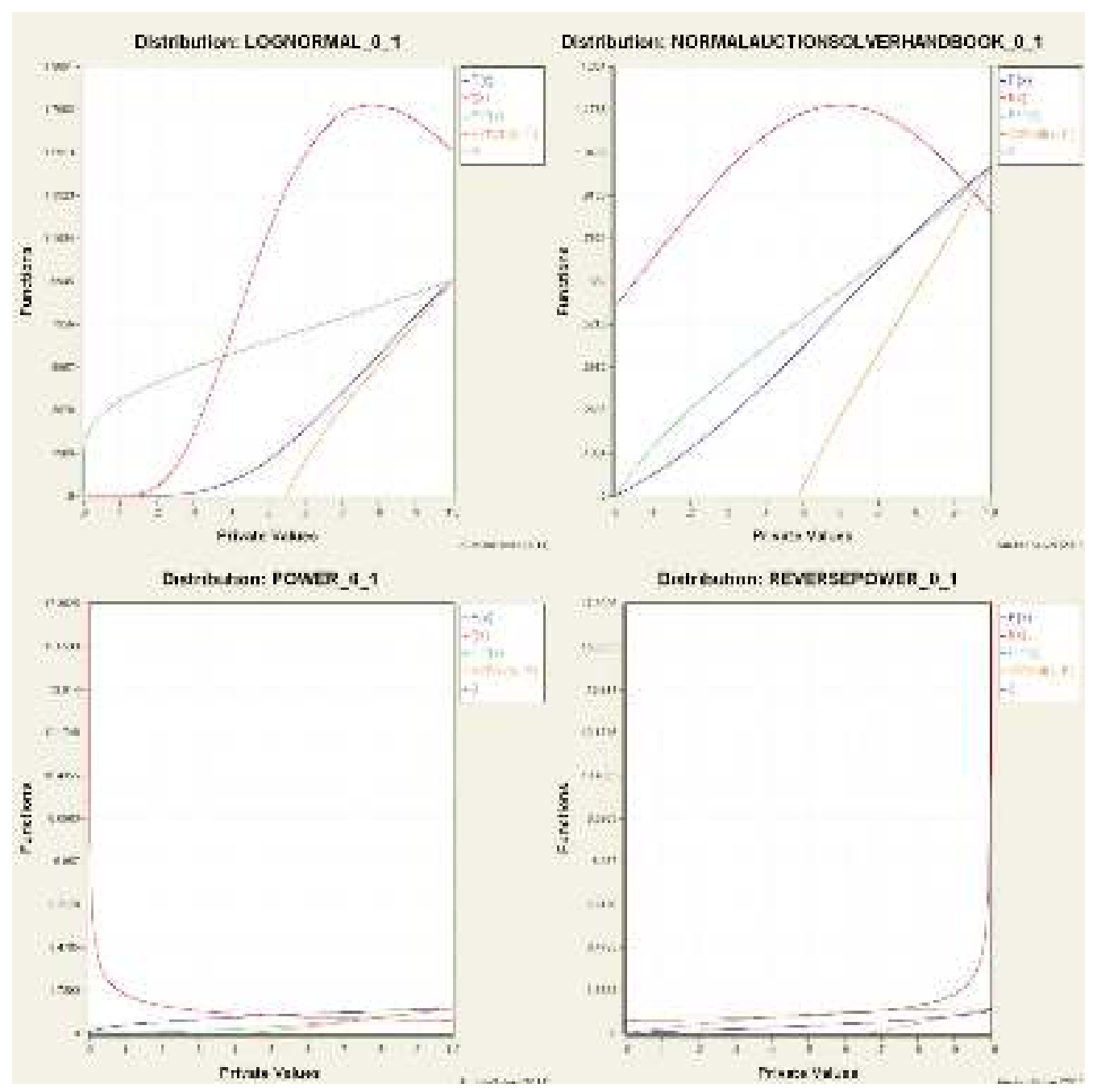


CEA Journal of Economics

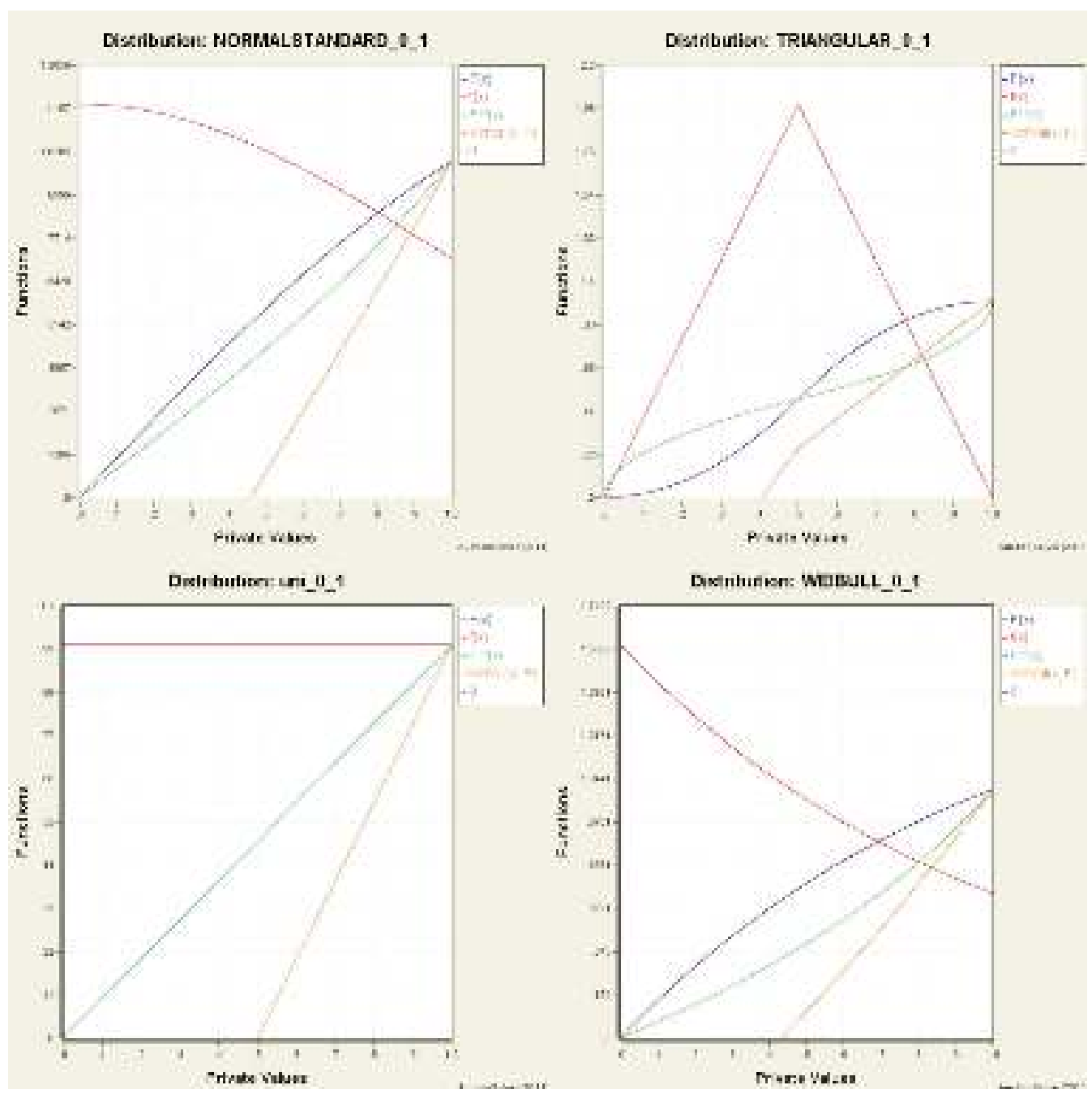




\section{References}

Baye, M.R., Kovenock, D., de Vries, C.G., 1996. The all-pay auction with complete information. Economic Theory 8 , 291-305.

Carl,S.,andBlume,L.,(1994), Mathematics for Economists (Student ed.). Viva Norton. p. 363. ISBN 978-81-309-1600-2.

Deb,R.,Pai,M.,M.,(2016), Discrimination via symmetric auctions, working paper

Gneezy, U. \&Smorodinsky, R. (2006). All-Pay Auctions - An Experimental Study. Journal of Economic Behavior and Organization, 61, 255-275.

Klemperer, P. (1999), Auction Theory: A Guide to the Literature, Journal of Economic Surveys, 13, 227-286.

Krishna, V.(2010): AuctionTheory, AcademicPress, SanDiego, 2010 (2nd edition).

Kunimoto,T.,(2008), Lecture note on auctions, Department of Economics , McGillUniversity

McAfee,P.,R., and McMillan,J., (1987),Auctions and bidding, Journal of economic literature, Vol.XXV,pp.699-738

Menezes, Flavio, M. , Monteiro ,Paulo K.,(2008), An Introduction to Auction Theory, Oxford University Press

Pardina,-Martinez,I.,(2006), First-price auctions where one of the bidders 'valuations is common knowledge, Review Economic Design 10(1):31-51

Riley, G., J., Samuelson,F.,W.,(1981),Optimal auctions, The American Economics Review,Vol.71,No.3.

Smith, L.,Vernon (2001), Markets, Institutions, and Experiments, Encyclopedia of cognitive science, University of Arizona, Tucson, Arizona, USA

Vickrey, William (1961). Counterspeculation, Auctions, and Competitive Sealed Tenders. The Journal of Finance 16 (1): 8-37.

Ockenfels,E.,Roth,A,E, (2003), Late and multiple bidding in second price internet auctions: theory and evidence concerning different rules for ending an auction, CESIFO working paper no. 992 